\title{
TELEVISÃO E SERIALIDADE: FORMATOS, DISTRIBUIÇÃO E CONSUMO
}

\author{
CRISTIANO MAX PEREIRA PINHEIRO \\ UNIVERSIDADE FEEVALE \\ NOVO HAMBURGO, RIO GRANDE DO SUL, BRASIL \\ E-MAIL: MAXRS@FEEVALE.BR \\ MAURICIO BARTH \\ UNIVERSIDADE FEEVALE \\ NOVO HAMBURGO, RIO GRANDE DO SUL, BRASIL \\ E-MAIL: MAURICIO@FEEVALE.BR \\ RAONA NUNES \\ UNIVERSIDADE FEEVALE \\ NOVO HAMBURGO, RIO GRANDE DO SUL, BRASIL \\ E-MAIL: RAONANUNES@GMAIL.COM
}

HTTP://DX.DOI.ORG/10.5902/2316882X22925 
TELEVISÃO E SERIALIDADE: FORMATOS, DISTRIBUIÇÃO E CONSUMO

Resumo: O trabalho propõe uma discussão acerca das séries de televisão, contribuindo, dessa forma, para o avanço do conhecimento no assunto e para a visão da ciência aplicada. Em seu escopo teórico, utilizam-se autores como Machado (2005), Carlos (2006), Balogh (2002), Pallottini (1998), Comparato (1995) e Sydenstricker (2012), entre outros. Após a exposição dos conceitos, entende-se que as séries de televisão estão inseridas nos meios de comunicação de massa e tornaram-se um produto cultural internacional. À partir desse cenário, nota-se que há, ainda, um caminho bastante amplo a ser percorrido dentro de sua análise estrutural; o que possibilita o estudo das especificidades desse formato narrativo, ainda pouco explorado se comparado a outros meios.

Palavras-chave: Séries. Televisão. Formato. Distribuição. Consumo.

\section{TELEVISION AND SERIALITY: FORMATS, DISTRIBUTION AND CON- SUMPTION}

Abstract: The paper proposes a discussion about the television series, thereby contributing to the advancement of knowledge on the subject and to the vision of applied science. In its theoretical scope, are used authors as Machado (2005), Carlos (2006), Balogh (2002), Pallottini (1998), Comparato (1995) and Sydenstricker (2012), among others. After exposure of the concepts, it is understood that TV series are inserted in the mass media and became an international cultural product. From this scenario, we notice that there is also a very broad way to go in its structural analysis; which enables the study of the specifics of this narrative format, yet underexplored compared to other means.

Keywords: Series. TV. Format. Distribution. Consumption.

TELEVISIÓN Y SERIALIDAD: FORMATOS, DISTRIBUCIÓN Y CONSUMO

Resumen: El documento propone una discusión acerca de la serie de televisión, lo que contribuye al avance del conocimiento sobre el tema y con la visión de la ciencia aplicada. En su ámbito teórico, se utilizan autores como Machado (2005), Carlos (2006), Balogh (2002), Pallottini (1998), Comparato (1995) y Sydenstricker (2012), entre otros. Después de la exposición de los conceptos, se entiende que las series de televisión se insertan en los

Rev.Cad. Comun. Santa Maria, v.20, n.2, art 6, p.2 de 19, maio/ago.2016 
medios de comunicación y se convirtieron en un producto cultural internacional. A partir de este escenario, nos damos cuenta de que hay también una manera muy amplia para ir en su análisis estructural; lo que permite el estudio de las características específicas de este formato narrativa, aún poco explorada en comparación con otros medios.

Palabras clave: Series. Televisión. Formato. Distribución. El consumo. 


\section{INTRODUÇÃO}

O estudo e o desenvolvimento de teorias para descrever e classificar a infinidade das narrativas e suas estruturas, é feito desde a origem da prática de contar histórias e acompanha a evolução da sociedade, começando com Aristóteles, em 335 a.C. Mais tarde, o problema da narrativa foi retomado por diversos pesquisadores e estruturalistas, como Vladimir Propp (1928/1983), Claude Bremond (1966), Todorov (1977), A. J. Greimas (1966) e Barthes (1971), procurando sempre aprofundar e complementar as teorias anteriores.

Quando Barthes (2008) explica que muitas tentativas ainda serão necessárias antes de se poder assegurar totalmente um modelo de análise da narrativa, entende-se que a busca por formas mais completas de compreender a estrutura das narrativas não cessa, porque também não cessa o processo de renovação dos meios que contribuem para o surgimento de novos formatos narrativos e a adaptação dos antigos.

Depois da literatura, do teatro, do cinema e de tantos outros meios narrativos, um dos mais recentes e cada vez mais populares entre a cultura de massa é a série de televisão. Além do grande número de produções disponível atualmente ${ }^{67}$, o acesso também se tornou facilitado, sendo possível assistir aos programas na TV aberta, na TV por assinatura, por download ou, ainda, por meio da TV online, em serviços de streaming ${ }^{68}$.

No entanto, como destaca Balogh (2002), independente do formato ou meio pelo qual consome-se a história, a forma como é construída a narrativa das tramas é a grande responsável por atrair e fidelizar os espectadores, que, no caso das séries, permanecem acompanhando os episódios e temporadas até o final.

Dessa forma, este trabalho propõe uma discussão acerca das séries de televisão, contribuindo para o avanço do conhecimento no assunto e para a visão da ciência aplicada. A pesquisa deixa, ainda, outras questões a serem exploradas em projetos futuros, como comparações com outros objetos, a fim de estabelecer ou não padrões na forma narrativa das sé-

67 Aproximadamente 200 novas temporadas são laçadas a cada ano, sejam de novas séries ou de séries que já estão em andamento, segundo dados apurados pelo site americano TV Line. Disponível em <http://goo.gl/oa46qb>. Acesso em: 23 abr. 2016.

68 Tecnologia que envia informações e conteúdos multimídia por meio da transferência de dados, utilizando a internet.

Rev.Cad. Comun. Santa Maria, v.20, n.2, art 6, p.4 de 19, maio/ago.2016 
ries, e análises quanto as especificações e diferenças entre uma produção e outras que possuem meios de distribuição diferentes, como TV aberta e streaming, por exemplo.

\section{TELEVISÃO E SERIALIDADE TELEVISIVA}

O conceito de televisão abrange uma complexidade de aspectos; seja como instituição, indústria, linguagem, fonte de informação ou forma de entretenimento, a televisão está em constante transformação, modificando-se ao passo de mudanças tecnológicas e sociais e, ainda, conforme a dinâmica cultural de cada sociedade.

A televisão caracteriza-se como um importante instrumento da comunicação, que é utilizado, por exemplo, pelo telejornalismo, para informar, como também para entreter, em grande parte com programas de ficção com narrativas seriadas, como telenovelas e séries. Assim, oferece ao telespectador a possibilidade de acesso às mais diversas experiências de realidade, informação, comunicação e entretenimento, sendo esse último considerado a sua principal função na sociedade de hoje.

Para compreender tal complexidade e o atual cenário da televisão como forma de entretenimento a partir de seus formatos seriados, é preciso buscar as raízes e origens da televisão no mundo, tanto do surgimento da sua tecnologia, quanto do desenvolvimento da sua programação e formas de distribuição. Desde a sua criação, a televisão tornou-se presença constante na sociedade, com suas produções exigindo uma recepção intensa e participante dos telespectadores.

Por ter se tornado uma grande extensão humana, segundo a definição de McLuhan (1971), a televisão consegue envolver e despertar sentimentos no telespectador, proporcionando uma experiência profunda, que nenhum outro meio é capaz de possibilitar da mesma maneira.

De acordo com os dados da Pesquisa Brasileira de Mídia 2015 (PBM 2015) ${ }^{69}$, realizada pelo Ibope, a televisão ainda é o meio de comunicação predominante no país. Segundo o levantamento, $95 \%$ dos brasileiros assistem TV regularmente e $74 \%$ a veem todos os dias. Esses números se valem da grande abrangência que a televisão possui. Para Machado (2005, p. 19), o termo se aplica a inúmeras possibilidades de produção, distribui-

69 Disponível em: <http://goo.gl/xwnRwe>. Acesso em: 24 mar. 2016.

Rev.Cad.Comun. Santa Maria, v.20, n.2, art 6, p.5 de 19, maio/ago.2016 
ção e consumo, compreendendo "desde aquilo que ocorre nas grandes redes comerciais, estatais e intermediárias, sejam elas nacionais ou internacionais, abertas ou pagas, até o que acontece nas pequenas emissoras locais".

\subsection{Formatos Seriados e Ficção Televisiva}

Segundo Machado (2005), o modelo de serialização audiovisual adotado pela televisão surgiu no cinema por volta de 1913, devido às mudanças que estavam acontecendo no mercado de filmes. Como os longas-metragens só podiam ser exibidos em salóes de cinema destinados à classe média, pois eram mais caros e também mais confortáveis, os filmes eram transmitidos de forma seriada para o público mais pobre da periferia nos chamados nickelodeons, espaços em que as pessoas ficavam em pé ou sentadas em bancos de madeira sem encosto. Com isso, os filmes atendiam às duas demandas: com a duração mais longa nos salões de cinema e, exibido em partes, nos nickelodeons.

No entanto, nem a televisão nem o cinema criaram a forma seriada da narrativa. Ela já começou a ser empregada nas formas epistolares de literatura (cartas, sermões, etc.) e nas narrativas míticas intermináveis (As mil e uma noites), tendo um grande desenvolvimento com a técnica do folhetim (MACHADO, 2005). Para Carlos (2006), o folhetim é a origem da narrativa seriada vista hoje nas séries de TV:

O folhetim, narrativa cujos capítulos eram entregues ao leitor em forma seriada em jornais e revistas, consolidou uma fórmula de consumo interessante para uma sociedade industrial que se constituía ao longo do século 19. A estrutura em capítulos já era padrão em romances, mas, na medida em que nela se acentua a temporalidade, com a entrega de segredos ao leitor de forma regular, se consolida uma fidelidade à base da tensão e da atenção (CARLOS, 2006, p.9).

Essa temporalidade é uma das principais características da linguagem dos formatos seriados, seja no decorrer do tempo dentro da própria narrativa, ou no tempo do espectador em assistir ao programa, com visitas diárias ou semanais aos episódios ou capítulos. Balogh (2002, p. 95) defende que "a descontinuidade, a interrupção, a fragmentação são características da linguagem televisual", e aponta como os principais formatos

Rev.Cad. Comun. Santa Maria, v.20, n.2, art 6, p.6 de 19, maio/ago.2016 
da ficção televisiva as séries e seriados ${ }^{70}$ (termos usados para denominar o mesmo produto), as minisséries e as telenovelas.

Boa parte do tempo de exibição da televisão é tomada por esses formatos da ficção televisiva, que contam os mais diversos tipos e gêneros de histórias, o que começou a ser feito na literatura; depois, se passou a fazer também em teatro e, mais tarde, no cinema. Pallottini (1998, p. 24) aponta que a ficção de TV utilizou toda a experiência desses meios, somados ainda aos recursos do rádio, para se transformar no que é hoje: "Tudo isso junto, teatro, narrativa, cinema, rádio [...] redundou nas histórias televisadas, cada vez mais atraentes, na medida em que veiculam um conteúdo intencionalmente simples, tornado interessante pela utilização de técnicas mais sofisticadas". Assim como Balogh (2002), Comparato (1995) e Pallottini (1998) defendem que os produtos de ficção televisiva que são apresentados em mais de um capítulo podem ser classificados como telenovela, série ou minissérie.

A telenovela é uma obra aberta, baseada em diversos grupos de personagens e de lugares de ação, com várias histórias que se inter-relacionam durante um longo período de tempo, que, em média, é 160 capítulos. Uma das características importantes da telenovela é que seus trabalhos de produção e gravação são iniciados antes da trama estar totalmente escrita. Com isso, há possibilidade de mudar detalhes e, até mesmo, os rumos da trama de acordo com a reação do público e o julgamento da crítica, desde que não alterem o caminho principal previsto pela sinopse (PALLOTTINI, 1998).

Já a série é uma história fechada em que um personagem ou um grupo de personagens vive pequenas histórias ou aventuras em cada episódio (COMPARATO, 1995). De modo geral, uma série pode ser estruturada de duas formas: a primeira delas é em episódios independentes que têm, cada um em si, uma unidade relativa. A trama ocorre seguindo uma unidade total, mas o telespectador não depende tanto dos episódios anterio-

\footnotetext{
70 Este trabalho entende que série e seriado têm o mesmo significado, se referindo ao formato como série: "sempre me pareceu inadequado o termo 'seriado', no sentido de 'um seriado'! A palavra é um adjetivo substantivado que foi tomando o lugar do termo próprio ‘série'. Como se diz um enlatado, um cozido, um trançado, etc. Na verdade, me parece que o uso popular foi aproximando os termos 'série' e 'programa seriado' até simplificar em 'um seriado'. Por isso, não vejo como fazer distinção substancial entre série e seriado, em bom português. [...]” (MENDES, 2010).
}

Rev.Cad.Comun. Santa Maria, v.20, n.2, art 6, p.7 de 19, maio/ago.2016 
res para entender um episódio isolado (PALLOTTINI, 1998). Sydenstricker (2012, p. 133) explica que "essa estrutura é destinada a quem desconhece o programa, mas que, de algum modo, está familiarizado com o ritmo e as estratégias dramatúrgicas das séries". Como será abordado na próxima seção deste trabalho, essa estrutura é comum nas produções chamadas sitcom (comédia de situação ou comédia de costumes).

A outra forma exige que o telespectador seja fiel ao programa e acompanhe todos os episódios, pois nem tudo é resolvido ou explicado numa única exibição. Nesse caso, os fatos mais conectados, estruturados em redes de conflitos mais ou menos complexas (SYDENSTRICKER, 2012). Essa estrutura ocorre mais comumente nas séries dramáticas, como também será detalhado nas páginas a seguir.

E, por último, a minissérie, que é transmitida num determinado número de partes, podendo ser curta (de dois a seis capítulos) ou longa (com até vinte capítulos), como se fosse uma minitelenovela, mas com um drama geralmente mais profundo. É uma obra fechada, com história, peripécias e final definidos antes do início das gravações; ou seja, tem continuidade absoluta, em que a unidade se completa na visão da totalidade dos capítulos.

É composta por uma trama básica importante, desenvolvida ao longo de todos os capítulos, à qual se acrescentam incidentes menores. Porém, não possui a multiplicidade de tramas que caracteriza a telenovela e a série. "A minissérie procura se conter num plot, num conflito básico, numa linha central de ação bem-definida, não comportando a diversidade de linhas de ação da telenovela, às vezes só consolidadas depois que ela já está em andamento" (PALLOTTINI, 1998, p. 29).

Antes mesmo do surgimento da televisão, o rádio conquistou boa parte da sua audiência graças ao formato seriado, com as "novelas que faziam rir e chorar, levando para o ar as suas comédias e dramalhões" (SAMPAIO, 1984, p. 204). No Brasil, desde os primórdios da televisão até os dias de hoje, as produções seriadas que mais fazem sucesso são as telenovelas, seguidas pelas minisséries (BALOGH, 2002).

Nos EUA, desde o surgimento da televisão já existia a programação seriada, com programas de variedades, comédias e dramas, quase sempre adaptados do rádio. Porém, só depois que a TV começou a desenvolver linguagem e identidade próprias, é que consolidou formatos semelhantes aos que estão no ar até hoje, com produções seriadas de diferentes gêneros. Destaque para as séries de TV, principalmente as americanas, que,

Rev.Cad. Comun. Santa Maria, v.20, n.2, art 6, p.8 de 19, maio/ago.2016 
como aponta Jost (2012), apresentam tramas cada vez mais complexas e produções mais sofisticadas, gozando de grande popularidade.

\subsubsection{Séries de TV}

Nos últimos anos, as séries de TV têm atraído milhões de espectadores, que aumentam a cada novo episódio exibido ou nova série lançada. Nos EUA, país que mais assiste televisão no mundo ${ }^{71}$, na temporada 2014-2015 (que corresponde aos meses entre setembro de 2014 e maio de 2015), a série de maior audiência da TV aberta americana contabilizou um número total de 17.4 milhões de espectadores, apenas assistindo ao vivo. A série que conquistou essa marca foi NCSI, da emissora CBS, segundo dados da Nielsen ${ }^{72}$. Entre as principais emissoras de TV americanas, abertas e fechadas, aproximadamente 200 novas temporadas ${ }^{73}$ são lançadas a cada ano, sejam de novas séries ou de séries que já estão em andamento.

Como visto anteriormente, existem, basicamente, dois tipos de estruturas que caracterizam as séries de TV: com episódios independentes, que não exigem que o público conheça ou acompanhe a trama de forma permanente; e as séries mais complexas e estruturadas, que precisam ser acompanhadas desde o começo da história. Souza (2004) conceitua o primeiro modelo como sitcom, que não possuem situações tão complexas, além de ter duração menor que as séries dramáticas.

Os episódios dos sitcoms têm cerca de 30 minutos de duração, com 24 ou 22 minutos de programa gravado e o restante destinado a intervalos comerciais. Já as séries dramáticas têm duração média de uma hora, sendo cerca de 47 a 48 minutos de gravação e os demais minutos destinados a comerciais (THOMPSON, 2003). Nas séries:

[...] cada episódio tem uma relação com o anterior, embora o compromisso com a continuidade não seja uma premissa. Como o sitcom, a cada nova temporada, novos elementos são adicionados à trama. Sua produção é mais esmerada, com um maior

71 Segundo o estudo global Barômetro de Engajamento de Mídia, realizado pela Motorola Mobility.

72 Nielsen Media Research - empresa encarregada de medir a audiência dos meios de comunicação americanos, equivalente ao IBOPE no Brasil.

73 Número com base nos dados apurados pelo site americano TV Line. Disponível em: <goo.gl/oa46qb>. Acesso em: 10 abr. 2016.

Rev.Cad.Comun. Santa Maria, v.20, n.2, art 6, p.9 de 19, maio/ago.2016 
número de locações, onde a ação se desenvolve com mais personagens, tendo vários núcleos de tensão [...]. Enquanto no sitcom a marca é a leveza na abordagem dos temas, aqui os assuntos são problematizados. As séries podem ser dramáticas, cômicas ou criminais (MESSA, 2006, p. 3).

O sitcom tem como principal característica a apresentação de situações engraçadas do cotidiano de gente comum, trabalhando a irreverência dos personagens e o humor dos diálogos. Surgiu com o rádio britânico, quando era chamado britcom, e com a influência da cultura americana passou a adquirir essas características cômicas. O primeiro sitcom americano produzido foi "I Love Lucy", exibido entre os anos de 1951 a 1957 com 179 episódios, sendo considerada a série mais importante dos primórdios da TV. Com a aceitação do público, o formato marcou a época e foi ganhando mais espaço nas redes de televisão de todo mundo, criando o modelo de sitcom utilizado atualmente (NOLL, 2013).

Os Estados Unidos e a Europa são considerados os maiores produtores de séries, tendo esses tipos de programa como "carro chefe" da programação (SOUZA, 2004). Para Messa (2006), sitcoms e séries não podem ser considerados apenas como mais uma forma de entretenimento, pois são fenômenos sociais que tratam de temas relevantes para a sociedade.

Com o intuito de diferenciar os dois formatos, D’Abreu (2010) aponta que a série pode abranger o documentário e a ficção, tratando temas como relações familiares, tópicos sobrenaturais, fantasia, adolescência, sexo, paranormalidade, guerra, casos médicos, etc. Já o sitcom mostra situações cômicas ficcionais vividas pelos personagens. Os episódios do sitcom não precisam seguir uma linha, podendo cada um tratar de um tema diferente. Por outro lado, as séries precisam dar continuidade ao tema tratado, sendo que um episódio é a continuidade de outro e cada temporada tem um tema central que norteia todos os episódios, tornando a trama mais complexa.

Para Carlos (2006), uma série consegue assumir maior complexidade dramatúrgica devido, em grande parte, a sua longa duração, que permite "ampliar o número de personagens, desenvolver suas personalidades, temperamentos e ações em um nível extremo de detalhe e, ao mesmo tempo, estabelecer inúmeros laços dramáticos entre eles" (p. 26). Além disso, o autor também cita como motivo para a longevidade das séries a perspectiva de sua transformação, proporcionada não só pela longa dura-

Rev.Cad. Comun. Santa Maria, v.20, n.2, art 6, p.10 de 19, maio/ago.2016 
ção, mas, também, pelo envelhecimento de três de seus agentes: o telespectador, o ator e o personagem, somados ainda ao autor.

Assim como essas características definidas pela longa duração do formato, outros fatores também contribuem para a complexidade das tramas. Com o tempo, as séries foram evoluindo e ganharam um novo desenho para seus personagens, romperam paradigmas temáticos e criaram o ensemble show, ou seja, o programa "povoado" por muitos personagens com tramas próprias que não necessariamente se resolvem num mesmo episódio ou numa mesma temporada (CARLOS, 2006).

Com o grande número de personagens e várias tramas secundárias acontecendo além do plot principal, os episódios das séries geralmente mostram diferentes pontos de vista, ora enfocando um ângulo da vida do protagonista, ora de determinados personagens do seu mundo, um de cada vez. Para Pallottini (1998, p. 46), “o foco de visão de cada episódio muda e deve mudar, [...] a visão de mundo dos autores é homogênea no fundamental, mas a ênfase pode estar no protagonista ou não, da mesma forma que o ponto de vista".

Já o primeiro episódio da série, chamado piloto, deve servir como apresentação geral da trama principal, mostrando de forma clara os personagens mais importantes e identificando-os, além de mostrar suas relações, modo de ser, crenças, desejos, objetivos de vida e o estágio que estão. $O$ piloto deve situar o telespectador sobre o universo da ficção, mostrando o problema inicial que deu origem ao estado atual dos personagens, apresentando a situação dramática que o protagonista vive (RODRIGUES, 2014).

Pallottini (1998, p. 79) aponta que o primeiro episódio tem "caráter de relativa unidade e integridade", pois, apesar de contar uma história completa, ele está contido na "unidade maior de todo o seriado, que the dá sentido e integridade final”. Nesse contexto, existe, basicamente, duas formas de iniciar o piloto:

[...] ou você começa com pequenos flashes de cada uma das tramas e subtramas que pretende desenvolver, [...] ou entra de uma vez no assunto principal e mostra-o claramente, deixando o espectador ciente do que é que o espera e do que deve espe$\operatorname{rar}$ (PALLOTTINI, 1998, p. 82). 
As duas teorias introduzem um ou mais conflitos, incitando o suspense para como eles serão resolvidos no decorrer da série. Entrando em contato com o plot principal da trama, o telespectador decide se a história lhe interessa ou não, determinando se continuará assistindo-a. Por isso, mais do que apresentar e expor os pontos principais da trama, o piloto deve ter uma boa história e instigar a curiosidade para o que virá nos próximos episódios da temporada, ou, como Pallottini (1998) caracteriza, deve ser interessante, movimentado e informativo, de forma concomitante e não alternativamente.

Balogh (2002) também se refere ao piloto, porém, sob uma visão mercadológica, caracterizando-o como um episódio de amostragem, que normalmente é mais longo que os episódios usuais, mas que traz os elementos principais característicos da sua estrutura padrão. A partir disso, a autora define que o piloto é o fator decisivo para que a série seja produzida e continue sendo veiculada: "o potencial da série é medido pela reação do público ao piloto, se for positivo, a série irá ao ar" (BALOGH, 2002, p. 103).

Nesse contexto, percebe-se que o primeiro episódio tem grande importância numa série de TV, tanto para a sua produção, quanto para a veiculação e o consumo, se tornando um fator determinante para que o programa continue sendo produzido, pois é responsável por conquistar o público e também os produtores.

Após o piloto, no que diz respeito à apresentação do restante dos episódios das séries de TV, não existe um padrão quanto ao número de episódios. Em geral, os programas possuem uma média entre 10 e 24 episódios por temporada. Porém, essas estruturas variam bastante, possuindo quantidades diferentes de acordo com características determinadas pelo modo de produção e sistema de distribuição: seja por canais da TV aberta, da TV por assinatura, ou ainda com as novas formas de distribuição e circulação possibilitadas pela internet.

2.2 Distribuição e Consumo das Séries de Tv

O surgimento das novas tecnologias de distribuição dos sinais de TV contribuiu para uma crescente segmentação do mercado, como também para a inserção do mercado internacional. A criação da TV por assinatura, por exemplo, impactou no desenvolvimento da programação segmentada, direcionada para públicos mais específicos. E, no Brasil, ainda contribuiu para a importação de programas estrangeiros, principalmente séries

Rev.Cad. Comun. Santa Maria, v.20, n.2, art 6, p.12 de 19, maio/ago.2016 
de TV, além da exportação de programas nacionais, como as telenovelas (CAPPARELLI; LIMA, 2004).

Inicialmente, a TV a cabo tinha como objetivo apenas melhorar o sinal das redes em locais onde a recepção fosse precária ou inexistente. Mas, como explica Squirra (1995), alguns fatores favoreceram a transformação da simples antena comunitária, que melhorava o sinal de recepção, no sofisticado e rentável sistema de TV por assinatura que existe hoje. São eles: a rápida propagação dos satélites domésticos; o desenvolvimento das superestações; e a introdução dos serviços pagos para a TV a cabo.

Dessa forma, o sistema pôde crescer e criar forças próprias com a chegada e a colocação em operação dos satélites de comunicação. Cresceu também com a estruturação das empresas operadoras e a liberação da cobrança pelos serviços oferecidos aos assinantes (SQUIRRA, 1995, p. 98).

Apesar do alto investimento para a implantação da nova tecnologia, tendo em vista que cada residência tinha que ser fisicamente conectada ao sistema, a adesão ocorreu de forma crescente. Durante os anos 60, existia cerca de 650 mil assinantes nos EUA. Já em 1975, o número já chegava a 9,8 milhões (SQUIRRA, 1995).

Nos anos 80, as maiores redes de televisão aberta dos EUA (NBC, CBS e $A B C$ ) tiveram uma queda considerável nas suas audiências para as redes de TV a cabo em crescimento (DUARTE, 1996). Nessa época, vários e importantes canais foram inaugurados, com destaque para HBO, ESPN, CNN, MTV, Nickelodeon e Disney Channel. Segundo Squirra (1995, p. 99), "eles mudaram o perfil da televisão no país e conseguiram lugar cativo na preferência da população". No Brasil, a tecnologia chegou de forma definitiva na segunda metade dos anos 80 , com a regulamentação da TV por assinatura em 1988 (DUARTE, 1996).

Duarte (1996) aponta que as redes de TV a cabo adotaram a estratégia de concentrar suas programações e audiências de forma segmentada, como também destacam Capparelli e Lima (2004, p. 87): “A televisão a cabo ou por satélite tem características diferentes, tornando-se temática e atingindo nichos específicos de audiência". Com isso, pode-se dizer que, assim como a TV aberta tinha como habilidade alcançar uma grande audiência, a TV por assinatura veio para focar em públicos mais seletivos e segmentados, geralmente não alcançados com a programação da TV con-

Rev.Cad.Comun. Santa Maria, v.20, n.2, art 6, p.13 de 19, maio/ago.2016 
vencional, transformando a relação entre telespectador e televisão.

O surgimento dessa indústria mudou a forma como as pessoas se relacionam com a TV, o que veem e como veem. A TV paga trouxe novos personagens e novas variáveis para a dinâmica do mercado de comunicações. Trouxe novas tecnologias e novas opções de informação e entretenimento (POSSEBON, 2009, p. 13).

Também nesse contexto, Squirra (1995, p. 104) acrescenta que "com o aumento da oferta de TVs por cabos e o crescimento do número de assinantes, as indústrias do cinema e do vídeo tiveram que incrementar a produção de programas para atender à crescente demanda", juntamente com o fato do aumento da demanda de uma programação concebida para um público específico.

Wolton (1996) define quatro causas que explicam o surgimento e o sucesso da televisão segmentada: a existência de novas tecnologias, que permitiram multiplicar os receptores e favorecer a interatividade; a existência de um público, de uma demanda (que nos dias de hoje é ainda maior, devido a individualidade e necessidade de assistir ao que interessa a cada um); a existência de um mercado, com empresas de comunicação capazes de produzir e oferecer esses programas diversificados; e a última é o desgaste da televisão geralista, que não consegue suprir a diversificação dos gostos do público. Com a televisão segmentada, a ficção televisiva ganhou força, surgindo cada vez mais produções com o formato seriado.

No cenário atual, Silva (2013, p. 3) propõe que uma das condições que contribui para o aumento das produções, o destaque e a popularidade das séries de TV é "o contexto tecnológico em torno do digital e da internet, que impulsionou a circulação das séries em nível global, para além do modelo tradicional de circulação televisiva". Com isso, o autor aponta que embora as TVs por assinatura tenham se popularizado desde o seu surgimento e aumentado o acesso às séries, são as formas atuais de consumo televisivo em suporte digital que contribuem para a ampliação das formas de produção e consumo audiovisual, com destaque para os sistemas de transmissão em streaming ${ }^{74}$.

74 A ideia básica do streaming é que as informações não são armazenadas no computador do usuário, não ocupando espaço no HD. O indivíduo apenas recebe o "stream", a transmissão dos dados, e então a mídia é reproduzida à medida que chega ao

Rev.Cad. Comun. Santa Maria, v.20, n.2, art 6, p.14 de 19, maio/ago.2016 
O crescimento do setor de TV on streaming pode ser percebido ao analisar os números da Netflix, uma das principais empresas do ramo, que chegou a marca de 75 milhões de assinantes em janeiro de 2016, com o serviço presente em 130 países $^{75}$. Com isso, a empresa divulgou que os assinantes assistiram a 42,5 bilhões de horas de filmes e séries de TV no serviço ao longo de 2015.

Esse tipo de serviço foi criado com o intuito de oferecer acesso ilimitado a conteúdos audiovisuais pela internet, sem a necessidade de fazer download. Boa parte do que é disponibilizado para streaming são programas de televisão, entre séries, programas esportivos, reality shows, documentários, infantis e programas de entrevista. E, além de servir como plataforma para acessar programas audiovisuais produzidos e já exibidos em outros canais, produtoras e distribuidoras, empresas como a Netflix também começaram a criar produções originais, principalmente de séries, apresentando uma nova forma de distribuição e de consumo para o formato, como comenta Silva (2015), no caso da Netflix:

[...] a maioria das séries são colocadas com temporadas completas de uma só vez à disposição do usuário: ele pode assistir todos os episódios de maneira sequencial sem ter que esperar pelo próximo numa semana futura (como ocorre nas produções televisivas de canais fechados e abertos) (SILVA, 2015, p.6).

Esse novo modo de assistir as produções possibilitado pelos serviços de TV pela internet recebe o nome de binge-watching. $O$ termo binge, em inglês, significa compulsão e foi adaptado para designar o comportamento de assistir a vários episódios de séries de uma vez só, o que antes era chamado de maratona. Para Silva (2015, p. 7), a prática não se trata apenas de assistir seguidamente a um conjunto de episódios, mas, sim, "possibilita que uma assinatura de preço módico torne o receptor o único responsável pela forma como irá consumir este produto. Ele não depende da lógica de exibição tradicional".

Além da facilidade de distribuição, circulação e consumo das séries, Silva (2013, p. 3) ainda indica outra condição para explicar o destaque e a

usuário, dependendo da largura de banda da sua internet para que os conteúdos sejam reproduzidos.

75 Disponível em: <http://goo.gl/VXyq3A>. Acesso em: 29 abr. 2016.

Rev.Cad.Comun. Santa Maria, v.20, n.2, art 6, p.15 de 19, maio/ago.2016 
popularidade dos programas dentro e fora dos modelos tradicionais de televisão: "é a que chamamos de forma, e está ligada tanto ao desenvolvimento de novos modelos narrativos, quanto à permanência e à reconfiguração de modelos clássicos". Para Balogh (2002), também é a forma como é construída a narrativa que atrai os espectadores e os mantêm acompanhando a série, sendo esse um dos principais fatores responsáveis pela popularidade cada vez maior dos produtos televisivos:

A percepção de que a narrativa é fundamental para o sucesso nos meios massivos já vem do cinema, o antecedente mais próximo da TV, que deixou de ser um pequeno comércio para ser um grande negócio quando consolidou seu desenvolvimento em linhas narrativas (BALOGH, 2002, p. 52).

À partir disso, pode-se dizer que seja consumida pela TV aberta, pela TV por assinatura ou por streaming, a experimentalização e adesão de novas formas de distribuição e consumo das séries se dá, em boa parte, pelo desenvolvimento da sua narrativa, que deve garantir, dentro das características que compõem as séries, a identificação e o interesse dos telespectadores.

\section{CONSIDERAÇÕES FINAIS}

As séries de televisão estão inseridas nos meios de comunicação de massa e tornaram-se um produto cultural internacional. Com origem americana, país que até hoje lidera o setor em número e qualidade das produções, as séries saíram da esfera limitada da TV a cabo, ganharam espaço nos canais abertos e se integraram ao fluxo de informações da internet. Isso contribuiu para a facilidade de acesso aos programas, aumentando o consumo por parte do público e, consequentemente, o número de séries produzidas, pois as emissoras investem cada vez mais em novas produções, buscando atender às demandas dos mais diversos perfis e tipos de telespectadores.

A popularidade alcançada por essa forma de entretenimento televisionado pode ser percebida não só pela quantidade de séries que estão em andamento atualmente, mas, também, pelo comportamento dos seus consumidores. Hoje em dia, seja nas conversas entre amigos, nas redes sociais ou em notícias sobre entretenimento, as séries costumam estar entre os assuntos mais pautados, abordando a expectativa para o lançamento

Rev.Cad. Comun. Santa Maria, v.20, n.2, art 6, p.16 de 19, maio/ago.2016 
da nova temporada, ou, então, comentando a reviravolta do último episódio de outra.

Com a ampliação, diversificação e reformulação das narrativas direcionadas à essas produções, as séries de TV conquistaram espaço com histórias e personagens cada vez mais complexos, além do desdobramento dos acontecimentos e conflitos de forma mais detalhada e instigante - 0 que é possibilitado, especialmente, pelo formato seriado, que pode dividir a trama em uma grande quantidade de episódios e dar mais atenção para pequenos detalhes.

À partir desse cenário, a vontade de compreender o processo narrativo das séries foi o principal motivador para o desenvolvimento deste trabalho. Desta forma, nota-se que ainda há um caminho bastante amplo a ser percorrido dentro da análise estrutural da narrativa das séries de TV, a fim de estudar e compreender as especificidades desse formato narrativo, ainda pouco explorado em comparação a outros meios.

\section{REFERÊNCIAS}

ABREU, Karen Cristina Kraemer; SILVA, Rodolfo Sgorla da. Histórias e tecnologias da televisão. 2011. Disponível em: <http://www.bocc.ubi.pt/pag/abreu-silva-historia-e-tecnologias-da-televisao.pdf>. Acesso em: 21 abr. 2016.

BALOGH, Anna Maria. O Discurso Ficcional na TV: Sedução e Sonho em Doses Homeopáticas. São Paulo: Editora da Universidade de São Paulo, 2002.

BARTHES, Roland. Introdução à análise estrutural da narrativa. 3. ed. Petrópolis: Vozes, 2008.

CAPPARELLI, Sérgio; LIMA, Venício A. de. Comunicação e televisão: desafios da pós-globalização. São Paulo: Hacker, 2004.

CARLOS, Cássio Starling. Em Tempo Real: Lost, 24 horas, Sex and the city e o impacto das novas séries de TV. São Paulo: Editora Alameda, 2006.

CESAR, Newton. Mídia eletrônica: a criação de comerciais para TV, rádio e internet. Rio de Janeiro: Coleção Base Design, 2008.

COMPARATO, Doc. Da criação ao roteiro. Rio de Janeiro: Rocco, 1995.

D’ABREU, Patrícia. "Descabimentos” de fala e formatação: a perspectiva da heterologia na análise narrativa da sitcom. In: Anais... Congresso Brasileiro de Ciências da Comunicação. Caxias do Sul: Anais Eletrônicos UCS, 2010. Disponível em: <http://www. intercom.org.br/papers/nacionais/2010/resumos/R5-2913-1.pdf>. Acesso em: 19 abr. 2016.

DUARTE, Luiz Guilherme. É pagar para ver: a TV por assinatura em foco. São Paulo: Summus, 1996.

Rev.Cad.Comun. Santa Maria, v.20, n.2, art 6, p.17 de 19, maio/ago.2016 
CADERNOS DE COMUNICAÇÃO

UNIVERSIDADE FEDERAL DE SANTA MARIA

FRANÇA, Vera V. A Televisão Porosa: Traços e Tendências. In: FREIRE FILHO, João. A TV em transição: tendências de programação no Brasil e no mundo. Porto Alegre: Sulina, 2009.

GANCHO, Cândida Vilares. Como analisar narrativas. São Paulo: Ática, 2000.

GILDER, George. A vida após a televisão: vencendo na revolução digital. Rio de Janeiro: Ediouro, 1996.

JOST, François. Do que as séries americanas são sintoma? Porto Alegre: Sulina, 2012.

MACHADO, Arlindo. A Televisão Levada a Sério. 4 ed. São Paulo: Editora Senac São

Paulo, 2005.

MCLUHAN, Herbert Marshall. A revolução na comunicação. 2.ed. Rio de Janeiro:

Zahar, 1971.

MESSA, Márcia Rejane. A cultura desconectada: sitcoms e séries norte-americanas no contexto brasileiro. UNIrevista, v. 1, n. 3, jul. 2006. Disponível em: <http://s3.amazonaws.com/lcp/alaic-telenovela_y_ficcion/myfiles/A\%20cultura\%20desconectada_6.pdf>. Acesso em: 1 mai. 2016.

NOLL, Gisela. Séries, Séries Cômicas e Sitcoms: debatendo gêneros e formatos na televisão brasileira. Anais... XIV Congresso de Ciências da Comunicação na Região Sul, 30 de maio a $1^{\circ}$ de junho de 2013. Disponível em: <http://portalintercom.org.br/anais/ sul2013/resumos/R35-1029-1.pdf>. Acesso em: 23 abr. 2016.

PALLOTTINI, Renata. Dramaturgia de televisão. São Paulo: Moderna, 1998.

POSSEBON, Samuel. TV por assinatura: 20 anos de evolução. São Paulo: Save Produção, 2009.

RODRIGUES, Sonia. Como escrever séries: roteiro a partir dos maiores sucessos da TV. São Paulo: Aleph, 2014.

SAMPAIO, Mario Ferraz. História do rádio e da televisão no Brasil e no mundo. Rio de Janeiro: Achiamé, 1984.

SILVA, Anderson Lopes da. A prática do binge-watching nas séries exibidas em streaming: sobre os novos modos de consumo da ficção seriada. Anais... $5^{\circ}$ Encontro de GTs - Comunicon, 5, 6 e 7 de outubro de 2015.

SILVA, Marcel Vieira Barreto. Cultura das séries: forma, contexto e consumo de ficção seriada na contemporaneidade. Anais... XXII Encontro Anual da Compós, Universidade Federal da Bahia, 04 a 07 de junho de 2013.

SOUZA, José Carlos Aronchi de. Gêneros e formatos na televisão brasileira. São Paulo: Summus Editorial, 2004.

SQUIRRA, Sebastião Carlos de Morais. Aprender telejornalismo: produção e técnica. São Paulo: Brasiliense, 1995.

SQUIRRA, Sebastião Carlos de Morais. O século dourado: a comunicação eletrônica nos EUA. São Paulo: Summus, 1995.

SYDENSTRICKER, Iara. Taxonomia das séries audiovisuais: uma contribuição de rotei-

Rev.Cad. Comun. Santa Maria, v.20, n.2, art 6, p.18 de 19, maio/ago.2016 
rista. In: BORGES, Gabriela; PUCCI JR., Renato Luiz; SOBRINHO, Gilberto Alexandre. Televisão: Formas audiovisuais de ficção e documentário. São Paulo: Instituto de Artes/ Unicam, 2012.

THOMPSON, Kristin. Storytelling in Film and Television. Cambridge/Londres: Harvard University Press, 2003.

WOLTON, Dominique. Elogio do grande público: uma teoria crítica da televisão. São Paulo: Ática, 1996.

\section{Cristiano Max Pereira Pinheiro}

Doutor em Comunicação Social; coordenador dos cursos de Jornalismo, Relações Públicas e Publicidade e Propaganda e professor do Mestrado em Indústria Criativa (Universidade Feevale).

\section{Mauricio Barth}

Mestre em Indústria Criativa; professor nos cursos de Jornalismo, Relações Públicas e Publicidade e Propaganda (Universidade Feevale).

\section{Raona Nunes}

Graduada em Jornalismo (Universidade Feevale).

Recebido em:30/06/2016

Aceito para publicação: 15/07/2016 